\title{
A NOTE ON DROSERA SEED DISPERSAL
}

JASON KSEPKA • Farmingdale • New Jersey •USA • jasonksepka@gmail.com

During my explorations last summer of the Pinelands of southern New Jersey, I went to one of my favorite places. Unfortunately, this site is also a favorite place for off-road vehicles. The Forked River Mountains, and the adjacent powerline and railroad right-of-way, have been very severely damaged by illegal off-road vehicle use. In recent years, a number of volunteers organized, developed a plan, purchased and planted local white cedar trees in an effort to stabilize the soil and begin restoration of the site.

I noticed that Drosera rotundifolia and D. intermedia seemed to have segregated themselves to slightly different spaces in the same area (Fig. 1). The nature of the site allows for fluctuations in surface water level, the results of which can be seen in differences where the plants grew. Differences in seed morphology might possibly be the cause of the observed segregation.

Drosera rotundifolia seeds have an elongated testa (Fig. 2). Like tiny sails, these seeds can float long distances and get deposited where the water splashes at the edges of a wetland or along any debris such as logs or sphagnum moss.

Drosera intermedia has an ovoid seed. Presumably this seed would be more likely to sink, or at least not move quite as far.

Differences in seed morphology might explain the pattern seen in Figure 1. It is possible that floating D. rotundifolia seed were deposited on the slightly higher and courser edge near the planted white cedars; whereas the ovoid $D$. intermedia seed is lower in the water and is deposited on the adjacent sand.

It should be noted that the difference in size of the seeds and the distances we are talking about here, are small. In most locations, these two species are found growing next to one another. The texture of the landscape is so complicated that many factors must contribute to where the seed lands and germinates. But in this particular location, my guess is that seed morphology might explain the distribution of the plants.

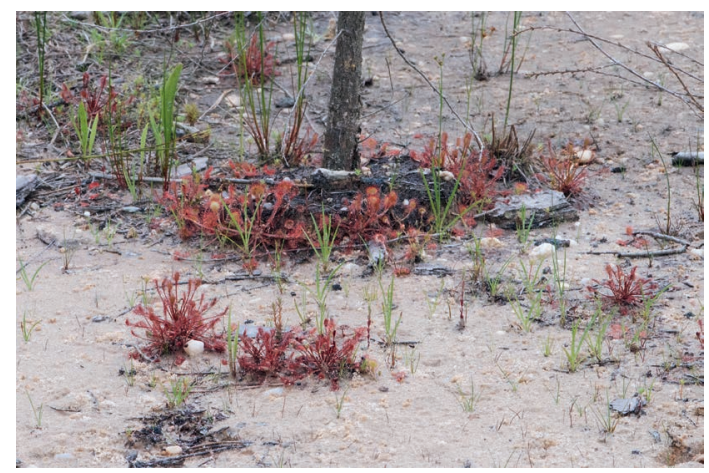

Figure 1: Segregation of Drosera intermedia (foreground) and D. rotundifolia (background).

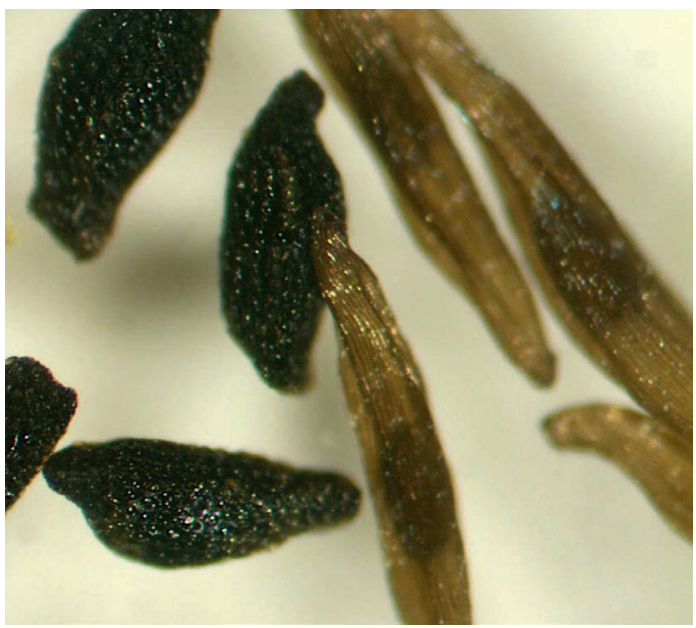

Figure 2: Drosera intermedia ovoid seeds (left) and $D$. rotundifolia with elongated testa (right). 